\title{
Are self-ligating brackets an advantageous alternative for non-extraction treatments?
}

\section{S. Gebeile-Chauty}

Qualified specialist in orthodontics - Lecturer and Hospital Orthodontist in Lyon

Former intern in the Lyon Hospitals - Private practice in Décines Charpieu

\begin{abstract}
The objective of this nonsystematic review of the literature is to determine whether or not self-ligating brackets are an equally effective alternative to traditional brackets for non-extraction treatments. The agreed upon criteria are indications for extractions, the biomechanical approach, the stability of the treatment results, the iatrogenic effects and the ergonomics.

The studies discuss arch expansion with the use of self-ligating brackets. One study mentions a lack of control of osseous management including tipping and buccal bone thickness in the lateral sectors. The mandibular incisor inclination that was obtained does not appear to be correlated to the type of bracket but rather to initial factors specific to the patient. We didn't find any study dealing with the long-term stability of the results.

Regarding patients, self-ligating brackets do not reduce the pain, the number of extractions, the incidence of resorption or the risk for caries.

Self-ligating brackets shortened the clinical time for an experienced practitioner but not the length of the time of comprehensive treatment and alignment. Some studies report an increase in cases of emergency. Finally, these brackets are more difficult to position.
\end{abstract}

\section{KEY WORDS}

Self-ligating brackets, biomechanics, iatrogenic, non extraction

Special thanks to: Hélène Pertuit

\section{INTRODUCTION}

Self-ligating brackets are sometimes presented as if they are part of an entirely separate type of orthodontic technique.
Defended by some ${ }^{18}$, and greeted with certain reservations by others, they are still hotly debated ${ }^{16}$. In addition to the opinions 


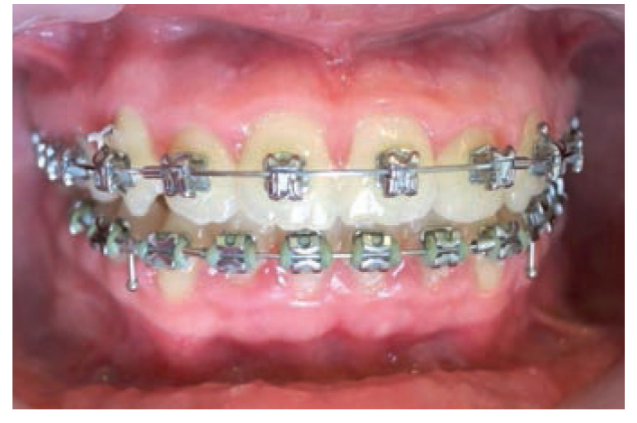

Figure 1

Self-ligating brackets in the context of our daily life: even though clinical experience is interesting, a survey of the bibliography allows for a science-based approach.

of experts (Fig. 1), the assessment of this technique can be done via the rapidly increasing literature on the subject.

Accordingly, the combination of the key search words "self-ligating orthodontic" on Medline Pubmed

\section{MATERIAL AND METHOD}

The criteria evaluated were the indications for extraction, the biomechanics, the stability of the therapeutic results, the iatrogenic effects and the ergonomics. produced 251 articles starting in $1990^{27}$, with an increase in articles after 2010.

The objective of this review of the literature is to determine whether or not self-ligating brackets are an equally effective or even better alternative to traditional brackets for nonextraction treatment.

Compared to conventional brackets, self-ligating brackets:

- do they reduce the indications for extraction?

- do they provide better biomechanics?

- do they increase the stability of the therapeutic results?

- do they reduce the iatrogenic effects?

- do they improve the ergonomics?

To accomplish this, we undertook a nonsystematic bibliographic survey on PubMed using the key words "self-ligating", "orthodontic", "comparison".

\section{RESULTS}

\section{Do self ligating brackets reduce the indications for extraction?}

There is no difference in the rate of extractions ${ }^{20}$.

\section{Do self-ligating brackets provide better biomechanics?}

\section{Force}

The forces required to move teeth are not as great for metal self ligating 
brackets compared to both conventional metal brackets and to self-ligating cermamic brackets ${ }^{17}$. Harradine $^{18}$ in his review of the literature reports minimal force for self-ligating brackets compared to 43-98 g per bracket with conventional brackets using elastomeric ligatures $^{18}$

The load deflection rate with $\mathrm{NiTi}$ is significantly greater with selfligating brackets ${ }^{31}$.

\section{Resistance to sliding}

The frictional force is lower with self-ligating brackets than with traditional brackets ${ }^{8,12}$. The friction resistance proved to be lower with ceramic and metal (stainless steel) self-ligating brackets than with conventional ceramic brackets ${ }^{39}$.

With the exception of single crystalline ceramic brackets, all the tested brackets (conventional brackets from Clarity $^{T M}$, Inspire Ice ${ }^{T M}$, Spirit $M B^{T M}$, and Mystique ${ }^{T M}$, and self-ligating brackets from Clarity $\mathrm{SL}^{\mathrm{TM}}$, In-Ovation $\mathrm{C}^{\mathrm{TM}}$, In-Ovation $\mathrm{R}^{\mathrm{TM}}$, and Smart Clip $^{\mathrm{TM}}$ ) offer a comparable rate of resistance to sliding based on the bracket (self-ligating or not) and on the material of the slot of the bracket ${ }^{35}$.

There was no difference in the rate of frictional resistance when steel wires were used between the traditional steel brackets, the conventional titanium brackets and the steel self-ligating brackets. On the other hand, when a TMA wire was used, the self-ligating brackets had a lower rate of friction than conventional brackets $^{22}$.
Passive self-ligating brackets (except for the ones from Smart Clip ${ }^{T M}$ ), offer less static and dynamic friction than the active and conventional brackets. However, in this experimental study, curiously enough, the material and the dimension of the archwire $^{19}$ that was used had no impact on the rate of friction.

Overall, during sliding, there was no difference in friction between the groups whether they were selfligating or not. However, when light force was applied, the frictional force delivered by the self-ligating brackets is weaker than that of the conventional brackets. The steel and not the $\mathrm{NiTi}$ was the most suitable archwire here. When strong force was applied, there was no difference in the frictional force delivered by self-ligating brackets as compared to force from conventional brackets regardless of the wire ${ }^{34}$.

Nonetheless, it is essentially important that minimal friction be combined with the necessary sliding mechanics ${ }^{22,34}$ (and therefore with closing extraction spaces that is not a problem in non extraction cases). Low friction might facilitate alignment and leveling according to the authors $^{12}$.

\section{Controlling the three orders}

\section{- Controlling the 1st order}

1) The consensus of the research is that all orthodontic treatments (with or without self-ligating brackets) bring about an increase in the dimensions of the arch. The expansion obtained is greater with self-ligating brackets than with conventional brackets ${ }^{11}$. 
At the end of treatment, the maxillary molars are more bucally inclined. The transverse dimensions are similar for both self ligating and non self ligating brackets. The inter-canine, inter-premolar and inter-molar distance increased in the two cases. However, it should be noted that cases with conventional brackets required using a quad helix whereas, with self-ligating brackets, the quad helix was not used ${ }^{3}$.

For other authors, the expansion in the arch length was significantly greater only between the molars when self-ligating brackets were used. The initial crowding and the Angle classification proved to be poor predictors for an increase in the intermolar distance 32 .

2) The expansion is greatest in the lateral sectors.

During non-extraction treatments (treated without stripping or distalization) with self-ligating brackets, the majority of variations of the transverse dimension took place in the premolar area (both the first and second at the same time in the upper and lower jaws). The maxillary intercanine distance increased by 0.75 $\mathrm{mm}$ and $1.96 \mathrm{~mm}$ in the mandibular arch. The inter-molar distance also showed a widening but to a lesser degree. All the transverse measurements proved to be equally significant with the exception of the width between the maxillary second molars ${ }^{28}$.

The greatest increase in arch width was noted between the first premolars $^{11}$.
In a randomized prospective study, the increase in the inter-molar distance is significant in the group treated with Smart Clip $^{T M}$ self-ligating brackets, even though it was only $0.91 \mathrm{~mm}$. On the other hand, variations in the inter-canine and interpremolar distance (first or second) were not correlated to the type of bracket $^{14,23}$.

Some authors (finally!) were interested in osseous effects in the course of an experiment using tomography on a dog with one side treated and one untreated side, that served as the control. They noted an achieved expansion with Damon ${ }^{\circledR}$ self-ligating brackets of $3.5 \mathrm{~mm}$ on average but they observed uncontrolled tipping of $15^{\circ}$, bone dehiscences but with no bone resorption. It might be interesting to have a control group treated with conventional brackets since, however a number of other studies mention frequent expansion, that is certainly smaller than when there are orthodontic treatments $^{3,11,21,28,32}$.

3) Changes in the dimension of the arch take place very early during orthodontic treatment.

Contrary to what is currently taught, changes in the arch take place very early during treatment with round $\mathrm{Ni}-\mathrm{Ti}$ wires and remain unchanged between the rectangular $\mathrm{Ni}-\mathrm{Ti}$ and the rectangular steel wire, regardless of the bracket (self ligating or conventional). In particular, the increase in the distance between the first and second premolar occurs when the alignment is finished. 
The time at which this change occurs is not affected by the choice of bracket $^{15}$.

\section{- Controlling the 2nd order}

A set up on a typodont model does not show any difference between the self-ligating and conventional brackets and if $0.016 \times 0.022$ stainless steel archwires are used ${ }^{7}$. This is perhaps related to the width of the brackets used in this study.

\section{- Controlling the torque}

A comparison of the various materials of the wires on self-ligating brackets shows that torque is best achieved with a stainless steel archwire, followed by a TMA archwire, followed by NiTi archwires. This is true for high torque values $\left(>24^{\circ}\right)$. Above $24^{\circ}$, stainless steel expresses 1.5 to 2 times more torque than the TMA and 2.5 to 3 times more than the NiTi. When low torque is involved $\left(<12^{\circ}\right)$ there is no difference no matter what the choice of the archwire material ${ }^{2}$. Active self-ligating brackets express torque better than passive ones. In fact, with a $0.019 \times 0.025$ in. stainless steel archwire (on a 0.022 inch slot bracket), for an active self-ligating bracket, the effective torque can be achieved with 15 to $31^{\circ}$ degrees of torque versus 23 to $35^{\circ}$ for a passive self-ligating bracket ${ }^{1}$.

\section{Achieved inclination of the maxillary incisor}

Clinically, there is no significant difference in the control of the torque of the maxillary incisors between the two types (self-ligating and conventional) of brackets for treatment without extraction ${ }^{23,33}$.

\section{Achieved inclination of the mandibular incisor}

There is no consensus: the majority of studies find no difference in the labial inclination or mandibular position between the self-ligating and non self-ligating groups $3,21,32$ and show that labial inclination and buccal position is in relation to other factors inherent to the patient.

Therefore, in cases without extraction, the vestibular position of the mandibular incisor in the group treated with Damon $^{\circledR} 3$ is not only in relation to the initial molar arch width and mandibular incisor crowding. It is also in relation to the skeletal pattern specific to the patient and related to the change in arch width obtained during treatment ${ }^{21}$.

The labial inclination achieved after treatment is correlated to the initial labial inclination and to the initial transverse dimensions ${ }^{14}$.

Only a few isolated studies have reported greater incisor labial inclination with conventional ${ }^{25}$ brackets or conversely more with self-ligating brackets $^{26}$.

\section{Managing anchorage}

There is no difference in anchorage between the groups and therefore self-ligating brackets do not help to increase anchorage ${ }^{26}$. 


\section{Do self-ligating brackets increase the stability of the treatment results?}

Currently, there is no proof that the results are more stable than those achieved with Damon ${ }^{\circledR 40}$ brackets.

In a systematic review of the literature, no study reported a better long term stability ${ }^{10}$.

An association of the key search words "self-ligating orthodontic stability" produced only two results. The study cited supra ${ }^{10}$ and one other work did not answer this question. Further study is necessary.

\section{Do self-ligating brackets reduce the iatrogenic effects?}

\section{Resorption}

No difference was shown between self-ligating and conventional brackets $^{20,24}$.

\section{Pain}

The research findings failed to prove that self-ligating brackets caused less pain than conventional brackets $^{3,9,40}$.

In a very recent study, the Smart Clip $^{\mathrm{TM}}$ brackets caused discomfort when the wires were placed and removed. However, a painless procedure contributes to the satisfaction of the patient ${ }^{4}$. Compared to conventional brackets, one study reported less discomfort with Damon ${ }^{\circledR}$ selfligating brackets than with conventional brackets $^{37}$, that was corroborated during alignment by Harradine's ${ }^{18}$ review that he attributed without a cause and effect proof to the lightweight wires and to the optimal gliding.

\section{Periodontium}

A randomized trial carried out on (only) 46 cases showed better results 5 weeks after the self-ligating brackets were attached in terms of halitosis, index of bleeding and dental plaque. On the other hand, there was no difference in the amount of bacterial colonization between the conventional and the self-ligating types of brackets ${ }^{29}$.

The periodontal index showed no significant difference ${ }^{3}$.

\section{Precarious lacunae}

One year later, there was no difference between the two types of brackets regarding the quantity of dental plaque or the presence of white spots. These results were corroborated in a randomized controlled trial that however only included 20 cases. The presence of precarious lacunae was related to hygiene and not to the type of bracket.

\section{Caries}

One study on streptococcus mutans showed no difference between the two types of brackets. Nonetheless, this systematic review of the literature was only able to pinpoint six high quality articles ${ }^{30}$. 


\section{Do self-ligating brackets improve ergonomics?}

\section{Length of treatment and number of office visits}

\section{- Number of office visits}

The various studies indicated a similar number of office visits ${ }^{9,20}$.

\section{- Length}

\section{Length of treatment}

The articles showed no difference in the length of treatment between self and non self-ligating brackets $9,16,17,18,26$.

In one study, the length of orthodontic treated was reported to significantly shorter with conventional brackets $^{20}$.

The factors that come into play in the length of treatment are different:

- the severity of the Class II and crowding, the space between the teeth, treatment plans with extractions ${ }^{17}$;

- the initial condition (assessed via the PAR index) $)^{26}$.

\section{Length of alignment}

The articles did not show any greater effectiveness for alignment ${ }^{32,16}$

At the start, during the first weeks, alignment is obtained more rapidly with conventional brackets. Subsequently, the difference in length is attenuated and turns out to be the same. The duration of treatment for alignment did not present any difference at an average period of 4 months $^{38}$.

There is no evidence that teeth align faster or in a different manner with Damon self-ligating brackets ${ }^{40}$.

\section{Time savings for the practitioner}

When the first publication on self-ligating brackets appeared on Pubmed in 1990, this was the argument that was put forward: time savings for the practitioner $^{27}$. Even today, this claim has still proven to be generally true according to the authors.

If the length of treatment time is identical, there is in fact some clinical timesavings with Damon $^{\circledR}$ self-ligating brackets but only when used by experienced practitioners ${ }^{40}$.

This time savings is approximately 20 seconds per arch when removing the archwires (not when installing the archwires) ${ }^{10}$.

However, sometimes, this clinical timesavings is negated by time loss related to emergencies due to unhooked or broken brackets ${ }^{13}$.

\section{Difficulty in placement for the practitioner}

Self-ligating brackets are significantly more difficult to position than conventional brackets. In relation to the FA point, Damon ${ }^{\circledR} \mathrm{XT}$ brackets are ten times less accurate than conventional Victory ${ }^{\mathrm{TM}}$ brackets. On the other hand, there isn't any greater amount of angulation error (tipping) with one type of bracket than the other ${ }^{5}$. 


\section{DISCUSSION}

\section{Discussion on the selected articles}

The number of high quality studies is inadequate ${ }^{16}$. Therefore, often:

- randomized trials have been done but there are too few ${ }^{14,24,29,38}$;

- samplings are low24,29,36;

- systematic reviews and metaanalyses only allow us to assess a few high caliber articles ${ }^{16,30}$.

In addition, it is important to note that most of the studies were carried out with just a few bracket models even though there are many different brands: Smart Clip $^{\mathrm{TM}}$ (3M Unitek, Monrovia, Calif) $4,5,8,14,26,35$; Damon $^{\circledR}$ (Ormco Corporation, Orange, Calif) 2,3,5,12,37,40; InOvationTM (Dentsply GAC, NY) $^{2,35}$; Speed $^{\mathrm{TM} 2}$.

\section{Discussion on the content of the articles}

The self-ligating bracket group showed a more significant increase in the width of the arch. What was this increase due to? Could it be the extended use of $\mathrm{NiTi}$ archwires that do not allow us to individualize the shape of the arch or the data contained in the brackets of the lateral zones in terms of torque that induces these changes in the arches?

This expansion of the arch can have esthetic consequences (full smile) but may have iatrogenic effects on the periodontium and lead to instability for the therapeutic results. However, we do not have any studies on the stability of treatments given the shortness of our clinical experience in dealing with them.

Currently, we have to contend with the constant evolution of brackets as well as the plethora of brackets on the market (active, passive...). Because of these two factors, we cannot assess the latest brands of brackets out there, and therefore still need a mid-term and long-term clinical track record for them.

\section{CONCLUSION}

Self-ligating brackets decrease frictional pressure. This does not reduce the amount of required anchorage.

The studies report a greater change in arch width dimension with the use of self-ligating brackets. Selfligating brackets appear to lead to an increase in interpremolar or molar distance. The mandibular incisor labial inclination achieved shows no significant difference between selfligating and non self-ligating groups and this does not seem to be correlated to the type of bracket but to initial factors specific to the patient. One study reported a lack of control of osseous management with regard to tipping and bone thickness labially in the lateral zones.

No study has been carried out on the long-term stability of results.

As for the patient, self-ligating brackets do not reduce the pain/ discomfort, do not decrease the 
number of extractions, do not diminish the amount of resorption, do not decrease the number of precarious lacunae.

The clinical time required for each office visit was reduced but the overall length of treatment time and time for alignment were not. Some studies reported more emergencies with self-ligating brackets but shorter practitioner work time.

Self-ligating brackets are more difficult to install.

Conflicts of interest: The author declares no conflict of interest.

\section{BIBLIOGRAPHY}

1. Archambault A, Lacoursiere R, Badawi H, Major PW, Carey J, Flores-Mir C. Torque expression in stainless steel orthodontic brackets. A systematic review. Angle Orthod 2010;80(1):201-10.

2. Archambault A, Major TW, Carey JP, Heo G, Badawi H, Major PW. A comparison of torque expression between stainless steel, titanium molybdenum alloy, and copper nickel titanium wires in metallic self-ligating brackets. Angle Orthod 2010;80(5):884-9.

3. Atik $\mathrm{E}$, Ciğer $\mathrm{S}$. An assessment of conventional and self-ligating brackets in Class I maxillary constriction patients. Angle Orthod 2014 Jan 14.

4. Bertl MH, Onodera K, Čelar AG. A prospective randomized split-mouth study on pain experience during chairsidearchwire manipulation in self-ligating and conventional brackets. Angle Orthod 2013;83(2):292-7.

5. Birdsall J, Hunt NP, Sabbah W, Moseley HC. Accuracy of positioning three types of self-ligating brackets compared with a conventionally ligatingbracket. J Orthod 2012;39(1):34-42.

6. Buck T, et al. Elastomeric-ligated vs self-ligating appliances: a pilot study examining microbial colonization and white spot lesion formation after 1 year of orthodontic treatment. Orthodontics (Chic.) 2011;12(2):108-21.

7. Butti AC, Mangiacapra R, Saporito I, Augusti G, Salvato A, Re D. Second order root control of self-ligating brackets and traditional brackets: a "typodont» study. Minerva Stomatol 2014;63(3):51-7.

8. Castro RM, Neto PS, Horta MC, Pithon MM, Oliveira DD. Comparison of static friction with self-ligating, modified slot design and conventional brackets. J Appl Oral Sci 201;21(4):314-9.

9. Čelar A, Schedlberger M, Dörfler $P$, Bertl M. Systematic review on self-ligating vs. conventional brackets: initial pain, number of visits, treatment time. J Orofac Orthop 2013;74(1):40-51.

10. Chen SS, Greenlee GM, Kim JE, Smith CL, Huang GJ. Systematic review of selfligating brackets. Am J Orthod Dentofacial Orthop 2010;137(6):726.

11. Chen YP, Li S. [Self-ligating vs. conventional brackets in the treatment of patients with Class II division 2 malocclusion: a clinical trial of dental and cephalometric analysis]. Zhonghua Kou Qiang Yi XueZaZhi 2012;47(3):139-43.

12. Cordasco G, Farronato G, Festa F, Nucera R, Parazzoli E, Grossi GB. In vitro evaluation of the frictional forces between brackets and archwire with three passive selfligating brackets. Eur J Orthod 2009;31(6):643-6.

13. Deshpande A, Srinivas N, Kumar KK, Mapare S. Comparison of Opal self-ligating brackets with manually ligating brackets. J Contemp Dent Pract 2012;13(4):494-503. 
14. Fleming PS, DiBiase AT, Sarri G, Lee RT. Comparison of mandibular arch changes during alignment and leveling with 2 preadjusted edgewise appliances. Am J Orthod Dentofacial Orthop 2009;136(3):340-7.

15. Fleming PS, Lee RT, Mcdonald T, Pandis N, Johal A. The timing of significant arch dimensional changes with fixed orthodontic appliances: data from a multicenter randomised controlled trial. J Dent 2014;42(1):1-6.

16. Fleming PS, O'Brien K. Self-ligating brackets do not increase treatment efficiency. Am J Orthod Dentofacial Orthop 2013;143(1):11-9.

17. Hamilton R, Goonewardene MS, Murray K. Comparison of active self-ligating brackets and conventional preadjusted brackets. Aust Orthod J 2008;24(2):102-9.

18. Harradine N. Self-ligating brackets increase treatment efficiency. Am J Orthod Dentofacial Orthop 2013;143(1):10-8, 11-9.

19. Huang TH, Luk HS, Hsu YC, Kao CT. An in vitro comparison of the frictional forces between archwires and self-ligating brackets of passive and active types. Eur $\mathrm{J}$ Orthod 2012;34(5):625-32.

20. Jacobs C, Gebhardt PF, Jacobs V, Hechtner M, Meila D, Wehrbein H. Root resorption, treatment time and extraction rate during orthodontic treatment with self-ligating and conventional brackets. Head Face Med 2014;10(1):2.

21. Jiang RP, Fu MK. [Non-extraction treatment with self-ligating and conventional brackets]. Zhonghua Kou Qiang Yi XueZaZhi 2008;43(8):459-63.

22. Khalid SA, Kumar $V$, Jayaram $P$. The comparison of frictional resistance in titanium, self-ligating stainless steel, and stainless steel brackets using stainless steel and TMA archwires: An in vitro study. J Pharm Bioallied Sci 2012;4(Suppl 2):S203-11.

23. Kraus CD, Campbell PM, Spears R, Taylor RW, Buschang PH. Bony adaptation after expansion with light-to-moderate continuous forces. Am J Orthod Dentofacial Orthop 2014;145(5):655-66.

24. Leite V, Conti AC, Navarro R, Almeida M, Oltramari-Navarro P, Almeida R. Comparison of root resorption between self-ligating and conventional preadjusted brackets using cone beam computed tomography. Angle Orthod 2012;82(6):1078-82.

25. Lombardo L, Ficara P, Maltoni I, Moser L, Guarneri MP, Siciliani G. Comparison of the anterior limit of the dentition in patients treated with self-ligating straight-wire, conventional straight-wire and standard edgewise appliances. ISRN Dent 2012;2012:748-758.

26. Machibya FM1, Bao X, Zhao L, Hu M. Treatment time, outcome, and anchorage loss omparisons of self-ligating and conventional brackets. Angle Orthod 2013;83(2):280-5.

27. Maijer R, Smith DC. Time savings with self-ligating brackets. J Clin Orthod 1990;24(1):29-31.

28. Maltagliati LA, Myiahira YI, Fattori L, Filho LC, Cardoso M. Transversal changes in dental arches from non-extraction treatment with selfligatingbrackets. Dental Press $\mathrm{J}$ Orthod 2013;18(3):39-45.

29. Nalçac. R, Ozat Y, Cokakoğlu S, Türkkahraman H, Onal S, Kaya S. Effect of bracket type on halitosis, periodontal status, and microbial colonization. Angle Orthod 2014;84(3):479-85.

30. Nascimento LE, Souza MM, Azevedo AR, Maia LC. Are self-ligating brackets related to less formation of Streptococcus mutans colonies? A systematic review. Dental Press J Orthod 2014;19(1):60-8.

31. Nucera R, et al. Influence of bracket-slot design on the forces released by superelastic nickel-titanium alignment wires in different deflection configurations. Angle Orthod 2014;84(3):541-7.

32. Pandis N, Polychronopoulou A, Makou M, Eliades T. Mandibular dental arch changes associated with treatment of crowding using self-ligating and conventional brackets. Eur J Orthod 2010;32(3):248-53.

33. Pandis N, Strigou S, Eliades T. Maxillary incisor torque with conventional and selfligating brackets: a prospective clinical trial. Orthod Craniofac Res 2006;9(4):193-8. 
34. Pliska BT, Beyer JP, Larson BE. A comparison of resistance to sliding of self-ligating brackets under an increasing applied moment. Angle Orthod 2011;81(5):794-9.

35. Pliska BT, Fuchs RW, Beyer JP, Larson BE. Effect of applied moment on resistance to sliding among esthetic self-ligating brackets. Angle Orthod 2014;84(1):134-9.

36. Polat Ö, Gökçelik A, Arman A, Arhun N. A comparison of white spot lesion formation between a self-ligating bracket and a conventional preadjusted straight wire bracket. World J Orthod 2008;9(2):e46-50.

37. Pringle AM, Petrie A, Cunningham SJ, McKnight M. Prospective randomized clinical trial to compare pain levels associated with 2 orthodontic fixed bracket systems. Am J Orthod Dentofacial Orthop 2009;136(2):160-7.

38. Wahab RM, Idris $\mathrm{H}$, Yacob $\mathrm{H}$, Ariffin $\mathrm{SH}$. Comparison of self- and conventionalligating brackets in the alignment stage. Eur J Orthod 2012;34(2):176-81.

39. Williams $\mathrm{CL}$, Khalaf $\mathrm{K}$. Frictional resistance of three types of ceramic brackets. J Oral Maxillofac Res 2014;4(4):e3.

40. Wright N, Modarai F, Cobourne MT, DibiaseAT. Do you do Damon ${ }^{\circledR}$ ? What is the current evidence base underlying the philosophy of this appliance system? J Orthod 2011;38(3):222-30. 